\title{
Extracellular ATP Increases Glucose Metabolism in Skeletal Muscle Cells in a P2 Receptor Dependent Manner but Does Not Contribute to Palmitate-Induced Insulin Resistance
}

\author{
Ana Miguel Cruz and Craig Beall* \\ Institute of Biomedical and Clinical Science, University of Exeter Medical School, Exeter, United Kingdom
}

Saturated fatty acids such as palmitate contribute to the development of Type 2 Diabetes by reducing insulin sensitivity, increasing inflammation and potentially contributing to anabolic resistance. We hypothesized that palmitate-induced ATP release from skeletal muscle cells may increase inflammatory cytokine production and contribute to insulin/anabolic resistance in an autocrine/paracrine manner. In C2C12

OPEN ACCESS

Edited by:

Nicolas J. Pillon

Karolinska Institutet, Sweden

Reviewed by:

Cesar Osorio,

Universidad Metropolitana de Ciencias de la Educación, Chile

Charles Affourtit,

University of Plymouth,

United Kingdom

*Correspondence:

Craig Beall

c.beall@exeter.ac.uk

Specialty section:

This article was submitted to

Striated Muscle Physiology,

a section of the journal

Frontiers in Physiology

Received: 29 May 2020

Accepted: 26 August 2020

Published: 25 September 2020

Citation:

Cruz AM and Beall C (2020) Extracellular ATP Increases Glucose Metabolism in Skeletal Muscle Cells in a P2 Receptor Dependent Manner

but Does Not Contribute

to Palmitate-Induced Insulin

Resistance.

Front. Physiol. 11:567378. doi: 10.3389/fphys.2020.567378 myotubes differentiated at physiological glucose concentrations $(5.5 \mathrm{mM})$, palmitate treatment $(16 \mathrm{~h})$ at concentrations greater than $250 \mu \mathrm{M}$ increased release of ATP and inflammatory cytokines IL-6 and MIF, significantly blunted insulin and amino acidinduced signaling and reduced mitochondrial function. In contrast to our hypothesis, degradation of extracellular ATP using apyrase, did not alter palmitate-induced insulin resistance nor alter release of cytokines. Moreover, treatment with ATP $\gamma \mathrm{S}$ (16 h), a nonhydrolysable ATP analog, in the absence of palmitate, did not diminish insulin sensitivity. Acute treatment with ATP $\gamma S$ produced insulin mimetic roles; increased phosphorylation of PKB (aka AKT), S6K1 and ERK and enhanced GLUT4-mediated glucose uptake in the absence of exogenous insulin. The increases in PKB and S6K1 phosphorylation were completely prevented by pre-incubation with broad spectrum purinergic receptor (P2R) blockers PPADs and suramin but not by P2 $\times 4$ or P2 $\times 7$ blockers 5-BDBD or A-438079, respectively. Moreover, ATP $\gamma$ S increased IL-6 yet decreased MIF release, similar to the cytokine profile produced by exercise. Acute and chronic treatment with ATP $\gamma$ S increased glycolytic rate in a manner that was differentially inhibited by PPADs and suramin, suggesting heterogeneous P2R activation in the control of cellular metabolism. In summary, our data suggest that the palmitate-induced increase in ATP does not contribute to insulin/anabolic resistance in a cell autonomous manner.

Keywords: ATP, skeletal muscle, insulin sensitivity, palmitate, IL-6, MIF, mitochondrial function

\section{INTRODUCTION}

Lipid overflow, particularly of saturated free fatty acids, contributes to the pathophysiology of Type 2 Diabetes (T2D) by reducing insulin sensitivity and enhancing inflammation and mitochondrial dysfunction (Wu and Ballantyne, 2017; Petersen and Shulman, 2018; Sergi et al., 2019). These impairments are predominant in skeletal muscle, resulting in loss of glucose clearance 
that accounts for $85-90 \%$ of the impairments in glucose homeostasis observed in T2D (Katz et al., 1983; Pendergrass et al., 2007). Lipid-induced muscle insulin resistance (IR) is brought about primarily by impaired insulin signaling due to build-up of lipotoxic species and due to increased levels of circulating proinflammatory cytokines. Lipotoxic moieties associated with the development of IR include ceramides (Summers, 2006), longchain fatty acyl-coenzyme A (Ellis et al., 2000), diacylglycerol (Itani et al., 2002) and acylcarnitines (Aguer et al., 2015), among others [recently reviewed by Bergman and Goodpaster (2020)]. Excess lipid availability also appears to negatively regulate anabolic sensitivity, demonstrated by anabolic resistance in overweight and obese individuals (Guillet et al., 2009; Murton et al., 2015; Beals et al., 2016); in humans following a continuous intralipid infusion (Stephens et al., 2015), in diet-induced obese rodents (Anderson et al., 2008; Masgrau et al., 2012) and in highfat fed men in a model of disuse-induced IR (Wall et al., 2020).

A proportion of skeletal muscle inflammation occurs due to immune cell infiltration of muscle adipose depots (Khan et al., 2015). Independently from this, treatment with saturated fatty acids, particularly palmitate, as the major dietary fatty acid in blood, enhances the release of cytokines such as interleukin 6 (IL-6) and activates the IKK/NF- $\kappa \mathrm{B}$ signaling cascade (Jove et al., 2005), which is associated with the development of skeletal muscle IR. IL-6 has been extensively characterized for its paradoxical roles in inflammation. Acute and transient exerciseinduced increases in IL-6 contribute to the regulation of glucose homeostasis, for example, by stimulating glucose production (Fischer, 2006; Pedersen and Febbraio, 2008; Wolsk et al., 2010; Eckardt et al., 2014), glucagon secretion (Barnes et al., 2014) and altering adipose tissue function (Brandt et al., 2012). In contrast, chronically elevated circulating IL-6 features in proinflammatory conditions and is associated with muscle wasting and IR (Kern et al., 2001; Pradhan et al., 2001). Other cytokines and myokines, such as macrophage migration inhibitory factor (MIF), are elevated in inflammatory conditions such as obesity (Dandona et al., 2004) and T2D (Yabunaka et al., 2000) and have modulatory roles in glucose homeostasis (Atsumi et al., 2007; Miyatake et al., 2014). It remains important to establish the autocrine and paracrine roles of these myokines in skeletal muscle IR and inflammation.

Palmitate can also enhance muscle ATP release in a pannexin hemi-channel-mediated manner (Pillon et al., 2014). Palmitateinduced extracellular ATP (eATP) acts as a chemoattractant for immune cells, suggesting that the nucleotide plays an important role in the immune cell infiltration seen in conditions characterized by chronic low-grade inflammation, such as obesity and T2D (Wu and Ballantyne, 2017). In other tissues, eATP (and degradation products) has been implicated in inflammation and IR, as seen in adipose tissue (Tozzi and Novak, 2017; Wu and Ballantyne, 2017); in blockade of insulin receptor signaling in hepatocytes by adenosine diphosphate (ADP) (Chatterjee and Sparks, 2012) and by impaired glucose clearance and hepatic insulin sensitivity in mice lacking the ectonucleotidase CD39 (Enjyoji et al., 2008).

ATP is released from skeletal muscle in response to electrical stimulation (Buvinic et al., 2009; Bustamante et al., 2014) and by contraction/exercise (Steensberg et al., 2000; OsorioFuentealba et al., 2013). eATP acts in an autocrine/paracrine manner by signaling via metabotropic P2Y and ionotropic P2X purinergic receptors (P2Rs) leading to increased intracellular calcium concentration $\left(\left[\mathrm{Ca}^{2+}\right]_{\mathrm{i}}\right.$ ) (Cseri et al., 2002; AbdulGhani et al., 2008; Ito et al., 2018) and transactivation and transinhibition of pathways such as MAPK/ERK and protein kinase C signaling cascades (Ito et al., 2018). eATP also acts as an important vasodilator (Mortensen et al., 2009) and likely contributes to muscle hypertrophy following exercise (Ito et al., 2018). Given the well-characterized pro-inflammatory roles of eATP in other tissues and enhanced ATP release following treatment with saturated fatty acids, we hypothesized that palmitate-induced increases in eATP may contribute to the development of insulin/anabolic resistance and inflammation in an autocrine/paracrine manner in skeletal muscle, in the absence of immune cells.

\section{MATERIALS AND METHODS}

\section{Chemicals}

Novo Nordisk Actrapid recombinant human insulin was used for cell treatments (Henry Schein, United Kingdom). ATP $\gamma$ S, PPADs, suramin, 5-BDBD, A-438079 were purchased from Tocris (Bristol, United Kingdom). Fluo-4 Direct and 50 x MEM amino acid solution were from Thermo Fisher Scientific (Loughborough, United Kingdom). ATP (adenosine 5'-triphosphate magnesium salt), apyrase, fatty acid-free BSA, palmitic acid and indinavir were purchased from Sigma Aldrich (Poole, United Kingdom).

\section{Cell Culture}

The C2C12 (ATCC CRL-1772, Mus musculus) murine myoblast cell line was kindly gifted by colleagues at the University of Dundee. Cell were maintained in growth medium below $70 \%$ confluence, incubated at $37^{\circ} \mathrm{C}$ in humidified $5 \% \mathrm{CO}_{2}$ incubators. Cells were differentiated at physiologically relevant glucose concentrations $(5.5 \mathrm{mM})$. For differentiation, cells were plated in plating medium and incubated for $48 \mathrm{~h}$ (reaching $100 \%$ confluence) before medium was changed to differentiation medium. Differentiation medium was changed every day for 6 consecutive days to replenish glucose. Experiments were conducted after 7 days of differentiation. Refer to Supplementary Methods for media composition and seeding densities.

\section{Immunoblotting}

Experiments in $60 \mathrm{~mm}$ dishes were terminated by media collection (for ATP and cytokine analysis) and cell lysis for protein extraction. Protein concentrations were determined by the Bradford method and lysates subjected to SDSPAGE and electrotransferred to nitrocellulose membranes. Total and phosphorylated proteins and loading controls were immunoblotted and semi-quantified by infrared fluorescence using the Licor Odyssey scanner. See Supplementary Methods for lysis buffer and antibody details. 


\section{Cytotoxicity Assessment}

Cell viability was assessed in $\mathrm{C} 2 \mathrm{C} 12$ myotubes using extracellular lactate dehydrogenase $(\mathrm{LDH})$ activity measured using a commercially available kit and according to manufacturer's instructions (LDH assay kit, Abcam, United Kingdom). Briefly, C2C12 myoblasts were differentiated as above for 6 days and treated with palmitate $(0-750 \mu \mathrm{M})$ or BSA controls for $16 \mathrm{~h}$ before LDH activity was measured. Medium collected after overnight treatment was centrifuged $(600 \times g$ for $10 \mathrm{~min})$ and supernatants incubated with WST and lactate dehydrogenase. LDH oxidizes lactate (producing NADH) which reacts with WST to generate a yellow color which was detected by absorbance $\left(\mathrm{OD}_{450 \mathrm{~nm}}\right)$ using Pherastar FS plate reader.

\section{ATP Quantification}

The extracellular concentration of ATP was measured using a commercially available assay kit and used according to manufacturer's instructions (ATPLite, PerkinElmer) and as previously described (Vlachaki Walker et al., 2017). See Supplementary Methods for details.

\section{Assessment of Cellular Metabolism}

Mitochondrial and glycolysis stress tests were performed according to manufacturer's instructions with minor modifications (Agilent, United Kingdom). Briefly, for mitochondrial stress tests, cells were treated for $16 \mathrm{~h}$ with palmitate or BSA controls and treated acutely with with oligomycin $(2 \mu \mathrm{M})$, FCCP $(1 \mu \mathrm{M})$ and rotenone/antimycin A (1:1 ratio, final concentration $1 \mu \mathrm{M})$. For glycolysis stress tests, cells were treated with ATP $\gamma \mathrm{S}$ (up to $16 \mathrm{~h}$ ) and treated acutely with glucose $(10 \mathrm{mM})$; oligomycin $(2 \mu \mathrm{M})$ and 2-deoxyglucose (2-DG, 50 mM). Refer to Supplementary Methods for details.

\section{Cytokine Quantification}

The levels of extracellular cytokines present in conditioned media from treated cells were quantified using enzyme linked immunosorbent assays (ELISAs). MIF and IL-6 were measured using mouse Duo-set ELISA kits (Bio-Techne, Abingdon, United Kingdom), performed according to manufacturer's instructions.

\section{Measurement of Intracellular Calcium}

Changes in intracellular calcium were assessed using the fluorescent calcium indicator Fluo-4 Direct as previously described (Ito et al., 2018), with minor modifications for the $\mathrm{C} 2 \mathrm{C} 12$ cells. Briefly, C2C12 myotubes were differentiated in clear, flat bottomed 96 well plates. After 7 days, cells were incubated with Fluo-4 Direct-containing phenol red free medium for $60 \mathrm{~min}$ and relative changes in fluorescence measured using a Pherastar FS plate reader. See Supplementary Methods for details.

\section{Measurement of Glucose Uptake}

Briefly, C2C12 myotubes were differentiated in 96-well plates for 7 days (as above). For palmitate experiments, cells were treated for $16 \mathrm{~h}$ with palmitate $(500 \mu \mathrm{M})$ or BSA control on day 6. On day 7, cells were serum starved for $2 \mathrm{~h}$ and glucose starved for 1-2 h before incubation with treatments and subsequent incubation with 2-DG (100 $\mu \mathrm{M}, 15 \mathrm{~min}) .2$ DG uptake into C2C12 myotubes was assessed using the Glucose Uptake-Glo assay (Promega, Southampton, United Kingdom). See Supplementary Methods for details.

\section{Statistical Analyses}

In Western blotting experiments, a One-sample $t$-test was used to determine significant changes in phosphorylation or total protein expression, relative to control (normalized to 1). For multiple group comparisons, a one-way or two-way analysis of variance with post hoc Bonferroni were used. Statistical tests were performed using GRAPHPAD PRISM software (Prism 7; GraphPad Software, La Jolla, CA, United States). Results are expressed as mean \pm standard error. $P$ values $<0.05$ were taken to indicate statistical significance.

\section{RESULTS}

\section{Palmitate Treatment Diminishes Insulin Sensitivity and Increases ATP Release}

Differentiation of myoblasts into myotubes at physiologically relevant glucose concentrations yielded myotubes that were sensitive to insulin $(10-100 \mathrm{nmol} / \mathrm{L})$, as measured by significant increases in $\mathrm{PKB}$ and S6K1 phosphorylation (Figures 1A,B). In addition, treatment with mixed essential amino acids (AA) enhanced S6K1 phosphorylation (Figure 1C). In the absence of palmitate, insulin and AAs significantly increased the levels of phosphorylated $\mathrm{PKB}$ and $\mathrm{S} 6 \mathrm{~K} 1$, however, in the presence of $500 \mu \mathrm{M}$ palmitate, insulin/AA-induced $\mathrm{PKB}$ and S6K1 phosphorylation was significantly attenuated (Figures 1Di-iii). We observed no change in extracellular ATP (eATP) levels with $250 \mu \mathrm{M}$ palmitate, but at $500 \mu \mathrm{M}$ palmitate, eATP levels were elevated approximately two-fold (Figure 1E). Treatment with $500 \mu \mathrm{M}$ palmitate did not alter cell viability (Figure 1F). As expected, palmitate treatment led to significant impairments in mitochondrial function with cells displaying reduced basal oxygen consumption rates (OCR; Figures 1Gi,ii), reduced oligomycin-sensitive OCR (a measure of ATP production; Figures $\mathbf{1 G i}$,iii), diminished spare respiratory capacity (Figures 1Gi,iv), increased proton leak (Figures 1G,Gv) and reduced coupling efficiency (Figure 1Gvi).

\section{Degradation of eATP Does Not Alter Palmitate-Induced Insulin Resistance and Cytokine Release}

In separate studies, we confirmed that palmitate, at proinflammatory concentrations, enhanced eATP and that apyrase degraded palmitate-induced eATP by $90 \%$ (Figure 2A). Palmitate treatment significantly blunted insulin and AAmediated phosphorylation of PKB and S6K1, however, apyrase treatment did not alter blunting of insulin/AA-mediated signaling (Figures 2Bi-iv). Palmitate significantly increased ERK1/2 phosphorylation and this was not altered by apyrase, 
A

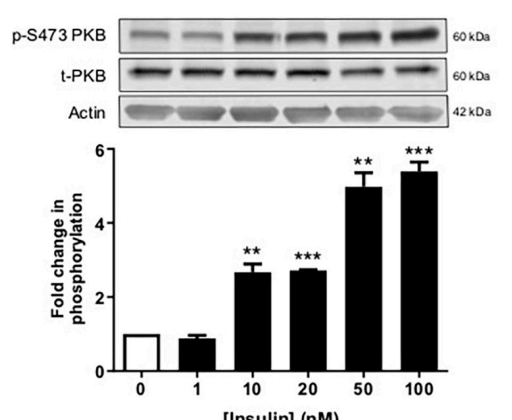

B
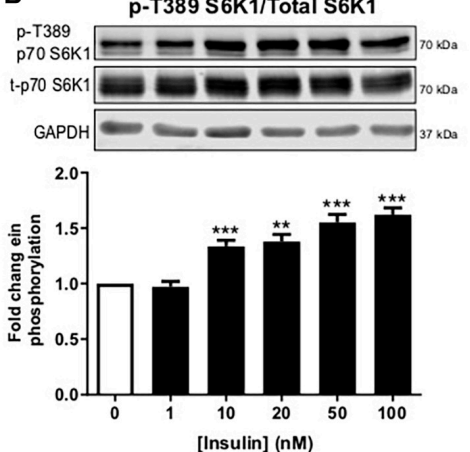

C
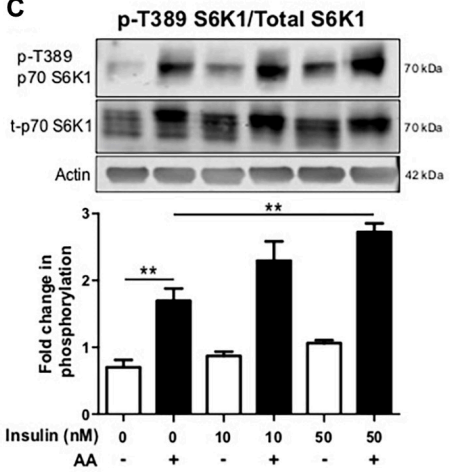

Di

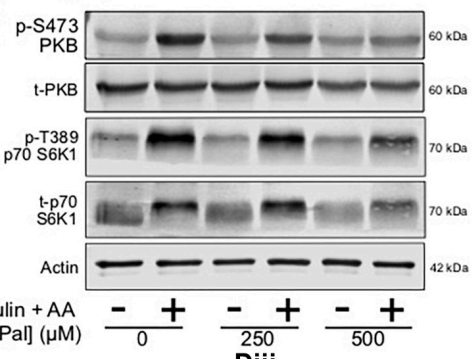

Dii

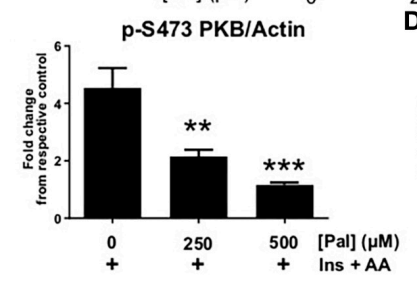

Gi

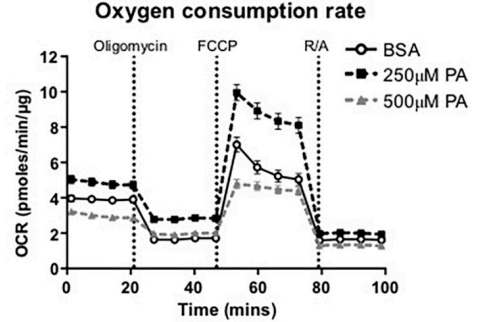

Giv

Spare respiratory capacity

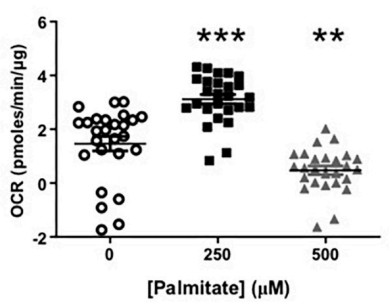

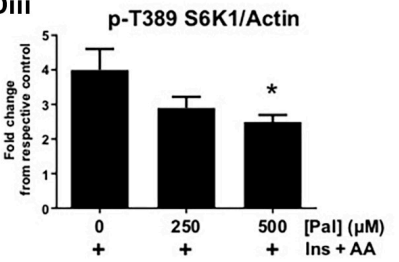

Gii

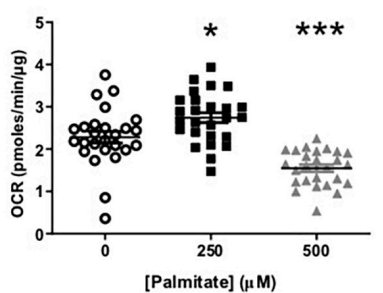

Gv

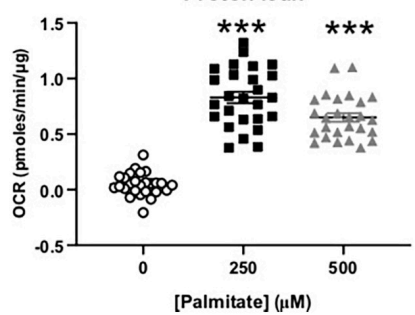

$\mathbf{F}$

eATP
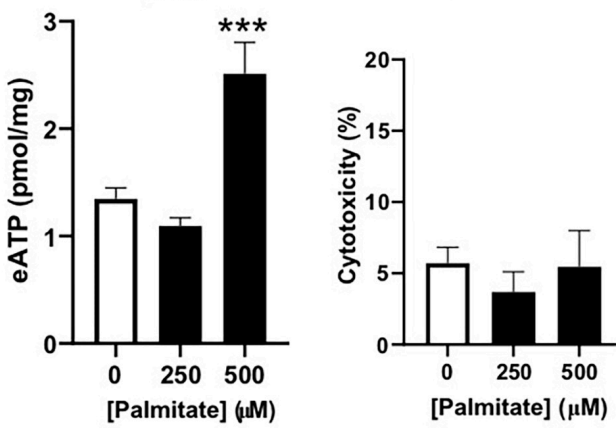

Giii

Oligomycin-sensitive OCR

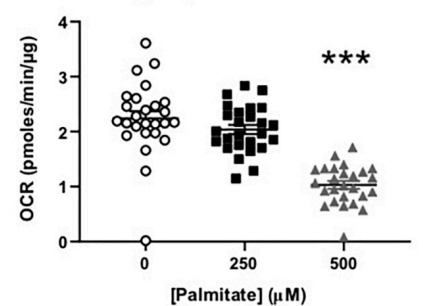

Gvi Coupling efficiency

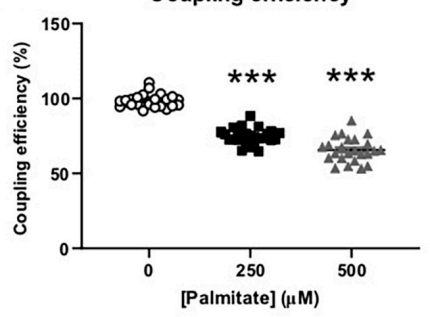

FIGURE 1 | Palmitate induces insulin resistance, enhances extracellular ATP and impairs mitochondrial function in C2C12 myotubes. Representative immunoblots for PKB (pS473) normalized to PKB (A) and p70-S6K1 (pT389) normalized to p70-S6K1 (B) with densitometric analysis below for cells treated with insulin (0-100 nM) for $60 \mathrm{~min}(n=4-7)$. Actin and GAPDH used as loading controls. (C) Representative immunoblot for p70-S6K1 (pT389) normalized to p70-S6K1 for cells treated for 60 min with amino acids (AA, $3.34 \mathrm{mM}$ ) or combined with insulin (0-50 nM) $(n=3)$. (Di) Representative immunoblots for PKB (pS473) and p70-S6K1 (pT389) normalized to actin with densitometric analysis in (Dii,iii), respectively, represented as fold change from respective control, for cells treated with palmitate (0-500 $\mu \mathrm{M}$; $16 \mathrm{~h}$ ) and insulin $(20 \mathrm{nM})$ and amino acids (AA, $3.34 \mathrm{mM})$ for $60 \mathrm{~min}(n=5-6)$. (E) Extracellular ATP measured by luminescence after palmitate treatment (0-500 $\mu \mathrm{M}$; $16 \mathrm{~h} ; n=7)$. (F) Cytotoxicity assessed by extracellular lactate dehydrogenase in palmitate (0-500 $\mu \mathrm{M} ; 16 \mathrm{~h})$ treated myotubes $(n=3)$. (Gi) Representative extracellular flux assay demonstrating oxygen consumption rate (OCR; pmoles/min/ $\mu \mathrm{g})$ at baseline and after acute injection of oligomycin $(2 \mu \mathrm{M})$, FCCP $(1 \mu \mathrm{M})$ and rotenone/antimycin $\mathrm{A}(\mathrm{R} / \mathrm{A} ; 1: 1$ ratio; $1 \mu \mathrm{M})$ at the indicated stages $(n=26-28)$. (Gii) Mean basal OCR before oligomycin. (Giii) Oligomycin-sensitive OCR measured as effect of oligomycin. (Giv) Spare respiratory capacity, measured as FCCP effect. (Gv) Proton leak measured as R/A effect. (Gvi) Coupling efficiency measured as the ratio between oligomycin-sensitive OCR and mitochondrial basal OCR expressed as percentage. ${ }^{\star} P<0.05,{ }^{\star \star} P<0.01$, ${ }^{\star \star \star} P<0.001$ against untreated control. 
A

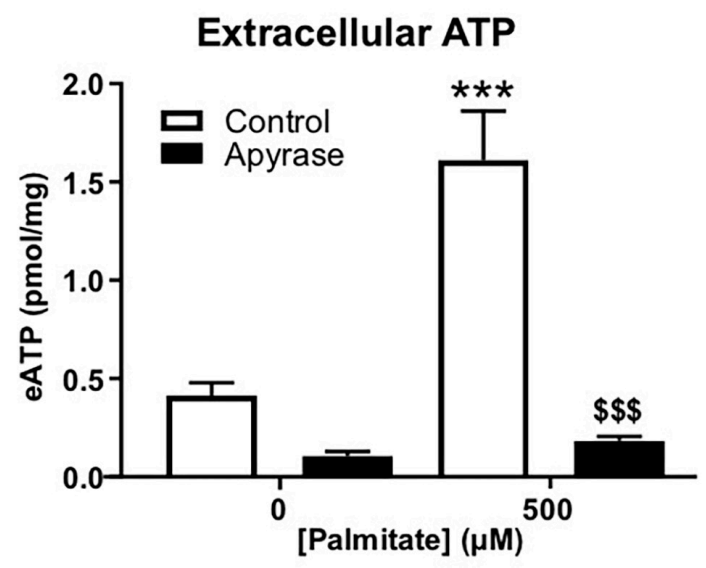

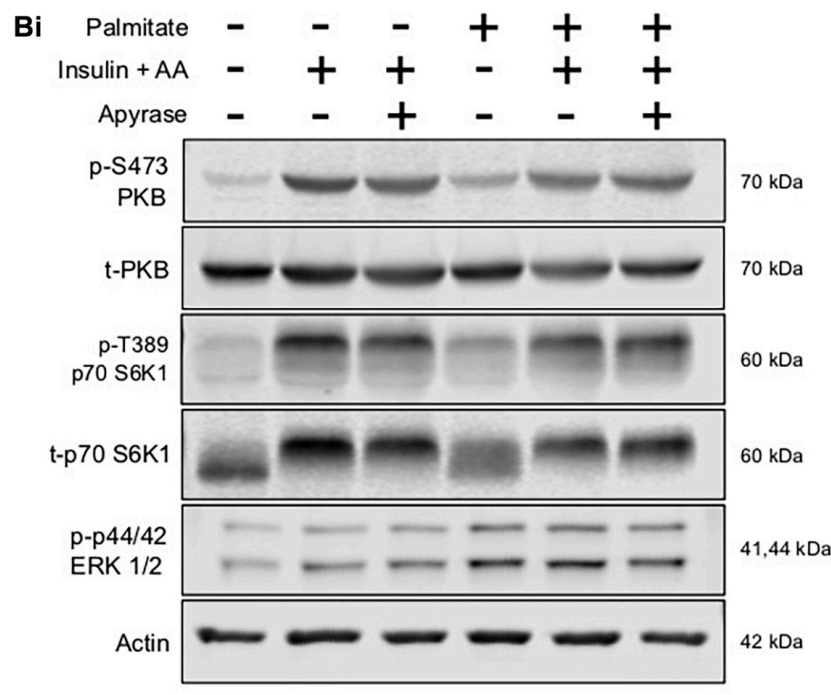

Biv

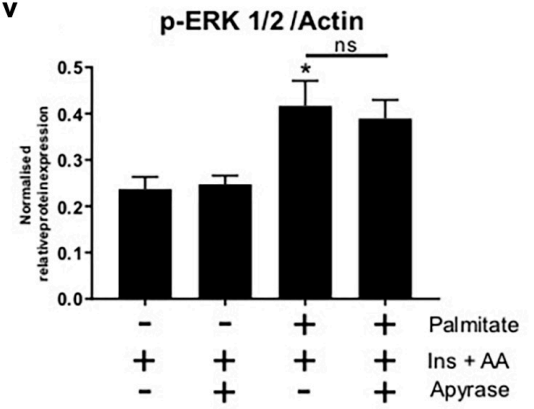

p-ERK 1/2 /Actin
C

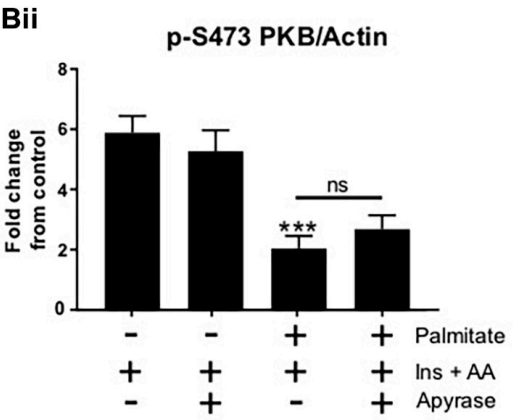

Biii p-T389 p70 S6K1/Actin

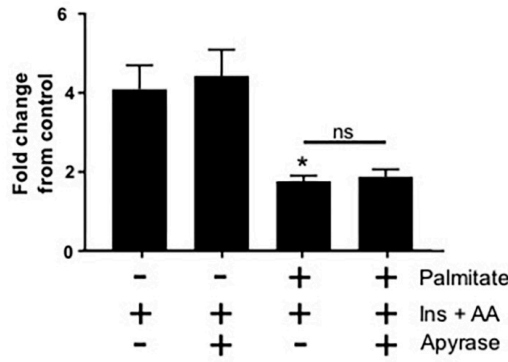

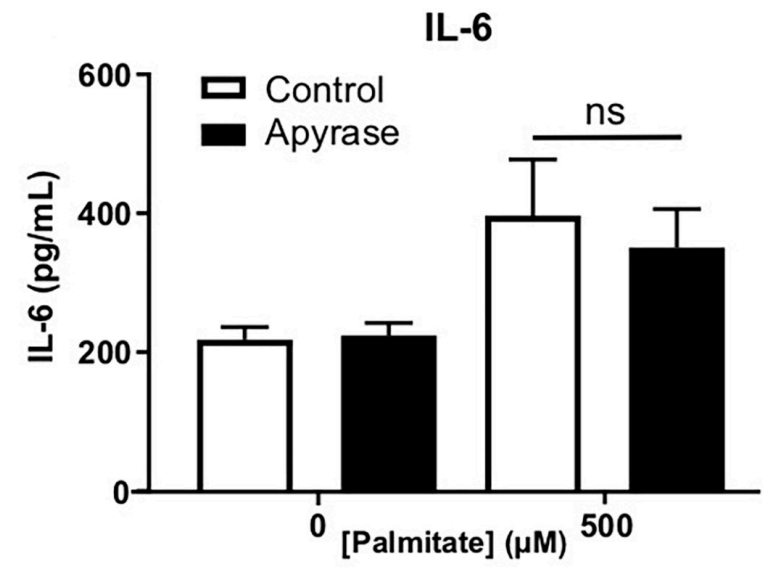

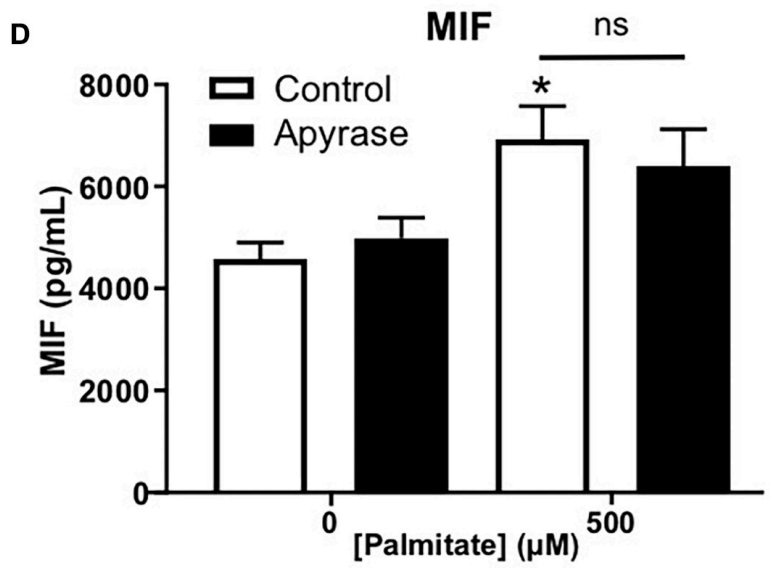

FIGURE 2 | Palmitate-induced insulin and anabolic resistance and cytokine release is not altered by hydrolysis of extracellular ATP with apyrase in C2C12 myotubes. (A) Palmitate-induced extracellular ATP $(500 \mu \mathrm{M} ; 16 \mathrm{~h})$ hydrolysed by treatment with apyrase $(0.5 \mathrm{units} / \mathrm{mL} ; 16 \mathrm{~h})$ in cells treated for $15 \mathrm{~h}$ with PA + apyrase and $1 \mathrm{~h}$ with insulin (20 nM) and amino acids (3.34 mM) $(n=6)$. (Bi) Representative immunoblots for PKB (pS473), total PKB, p70-S6K1 (pT389), p70-S6K1, ERK 1/2 (pThr202/Tyr204) and actin $(n=6)$ for cells treated as in A. Densitometric analysis for PKB (pS473) normalized to PKB (Bii) p70-S6K1 (pT389) normalized to p70-S6K1 (Biii) and ERK 1/2 (pThr202/Tyr204) normalized to actin (Biv). (C,D) Hydrolysis of extracellular ATP with apyrase (0.5 units/mL; 16 h) did not alter the palmitate (500 $\mu \mathrm{M} ; 16$ h)-induced increase in release of cytokines IL-6 (C; $n=6)$ or MIF (D; $n=5)$. ${ }^{\star} P<0.05,{ }^{\star \star \star} P<0.001$ for palmitate against control and ns $=$ not significant for the effect of apyrase on palmitate response. $\$ \$ P<0.001$ against palmitate treated group.

suggesting that additional mechanisms contribute to the palmitate-induced phosphorylation of ERK1/2 (Figures 2Bi, iv). We noted a modest increase in IL- 6 and a significant increase in macrophage migration inhibitory factor (MIF) induced by palmitate but this was not significantly modified by apyrase (Figures 2C,D). Taken together these data indicate that eATP 
does not contribute to palmitate-induced insulin resistance nor does it significantly contribute to palmitate-induced cytokine release from skeletal muscle.

\section{ATP $y$ S Treatment in the Absence of Palmitate Does Not Alter Insulin Sensitivity but Does Alter Cytokine Secretion}

To confirm ATP-induced signaling in C2C12 myotubes, intracellular calcium responses were monitored following ATP treatment. ATP caused a concentration-dependent increase in intracellular calcium, indicating P2R-mediated signaling (Figures 3A,B). To determine whether enhanced P2R-mediated signaling could alter insulin sensitivity, in the absence of palmitate, myotubes were incubated with a non-maximal concentration of ATP $\gamma \mathrm{S}$ (based on changes to intracellular calcium levels), a non-hydrolysable ATP analog, for $16 \mathrm{~h}$ prior to acute insulin treatment. As expected, acute insulin treatment increased $\mathrm{PKB}$ and $\mathrm{S} 6 \mathrm{~K} 1$ phosphorylation but this was not modified by ATP $\gamma \mathrm{S}$ pre-treatment (Figures 3C,D). Interestingly, when measuring release of IL-6 and MIF from $\mathrm{C} 2 \mathrm{C} 12$ cells treated with ATP $\gamma \mathrm{S}$, we observed a significant concentrationdependent increase in IL-6 release (Figure 3E). In contrast to the palmitate response, however, we observed a significant reduction in MIF release following ATP $\gamma$ S treatment (Figure 3F).

\section{Acute ATP $\gamma$ S Treatment Increases PKB and S6K1 Phosphorylation in a P2R-Dependent Manner and Enhances GLUT4-Mediated Glucose Uptake in Healthy but Not Palmitate-Challenged Cells}

To examine ATP $\gamma \mathrm{S}$ signaling in more detail, C2C12 myotubes were treated acutely with ATP $\gamma \mathrm{S}$ and $\mathrm{PKB}$ and S6K1

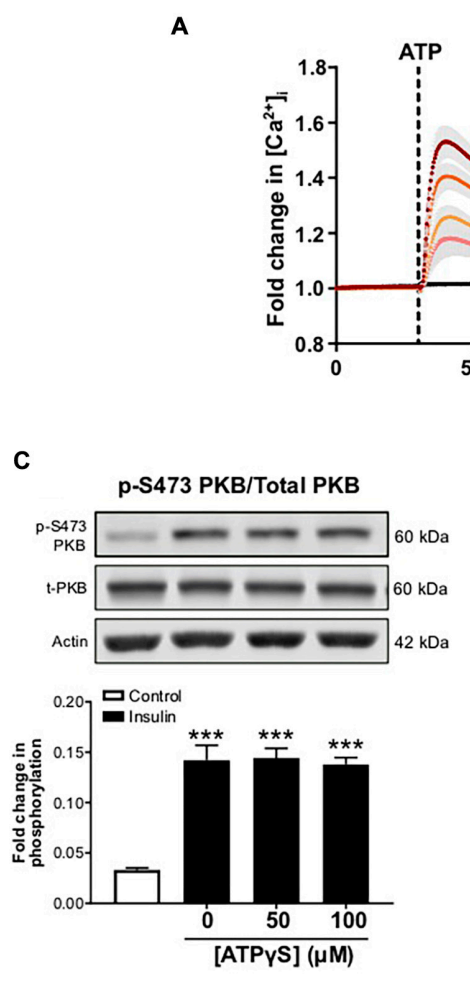

$\left[\mathrm{Ca}^{2+}\right]_{\mathrm{i}} \quad[\mathrm{ATP}](\mu \mathrm{M})$

-0
-30

-30
-50

- 100

$-200$

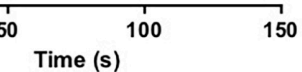

D
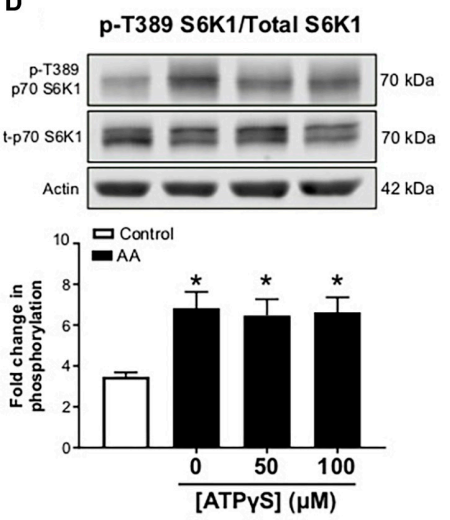

B

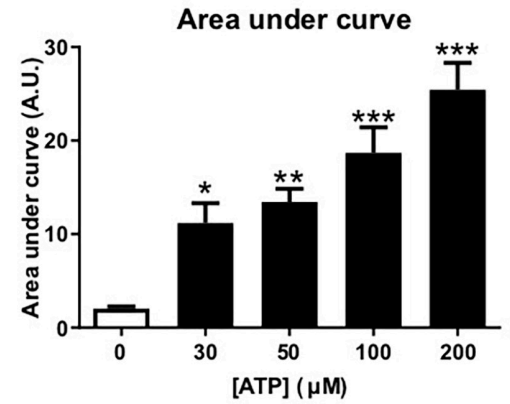

E
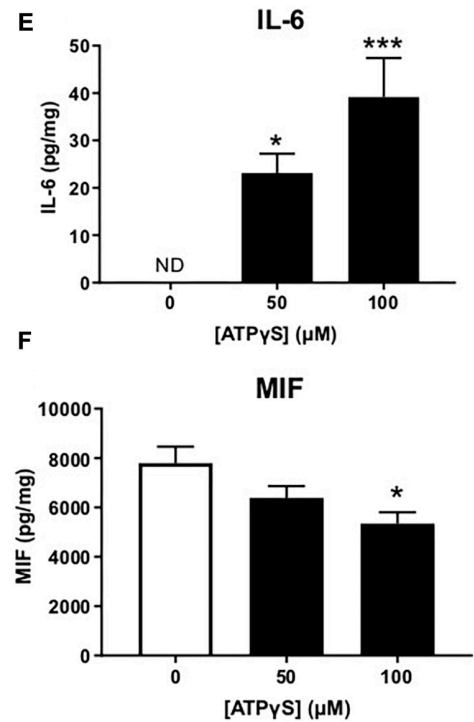

FIGURE 3 | Treatment with exogenous ATP increases intracellular calcium and alters cytokine release without impairing anabolic sensitivity in C2C12 myotubes. (A) Cells loaded with Fluo 4 direct for 60 min. Concentration-dependent increase in intracellular calcium assessed by change in fluorescence (RFU) with ATP $(0-200 \mu \mathrm{M} ; 30 \mathrm{~s}$ ) with area under the curve in (B) $(n=6)$. (C) Representative immunoblot and densitometric analysis for PKB (pS473) normalized to PKB following $16 \mathrm{~h}$ treatment with 50-100 $\mu \mathrm{M}$ ATP $\gamma \mathrm{S}$ and $1 \mathrm{~h}$ treatment with insulin $(20 \mathrm{nM})$ or control $(n=6)$. (D) Representative immunoblot and densitometric analysis for p70-S6K1 (pT389) normalized to p70-S6K1 following $16 \mathrm{~h}$ ATP $\gamma$ S treatment and $1 \mathrm{~h}$ treatment with mixed essential amino acids (AA, $3.34 \mathrm{mM})$ or control $(n=6)$. (E,F) Exogenous ATP $\gamma \mathrm{S}(50-100 \mu \mathrm{M} ; 16 \mathrm{~h})$ enhanced IL-6 release $(\mathrm{E} ; n=6)$ and suppressed MIF release $(\mathrm{F} ; n=6) .{ }^{*} P<0.05,{ }^{* *} P<0.01,{ }^{* \star *} P<0.001$ against vehicle control. 
phosphorylation was examined. Correlating with recent studies (Osorio-Fuentealba et al., 2013; Ito et al., 2018), we observed significant increases in phosphorylation of both $\mathrm{PKB}$ and S6K1 following ATP $\gamma \mathrm{S}$ treatment (Figures 4A,B). To determine which $\mathrm{P} 2 \mathrm{Rs}$ may be responsible, myotubes were pre-incubated with broad-spectrum P2R blockers PPADs and suramin, in addition to $\mathrm{P} 2 \times 4$ and $\mathrm{P} 2 \times 7$ antagonists, 5-BDBD and A-438079. Interestingly, PPADs significantly blocked ATP $\gamma$ S-induced increases in PKB, S6K1 and ERK1/2 phosphorylation while suramin significantly attenuated the latter two and modestly but not significantly attenuated PKB phosphorylation. Moreover, basal phosphorylation was also reduced, indicating tonic receptor activation (Figures $4 \mathrm{Ci}-\mathbf{i v}$ ). Acute treatment with ATP $\gamma \mathrm{S}$ enhanced glucose uptake in a concentration dependent manner, independently of insulin (Figure 4D). In addition, pre-treatment with GLUT4 inhibitor
A

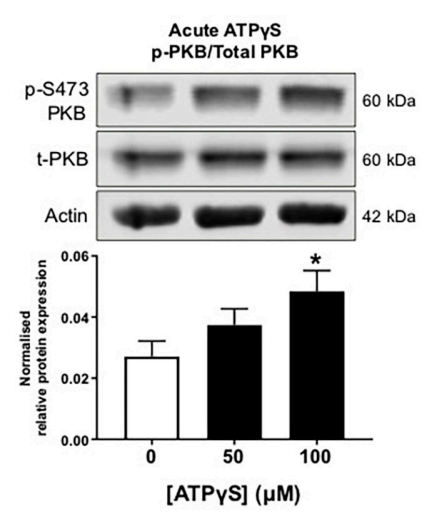

Cii

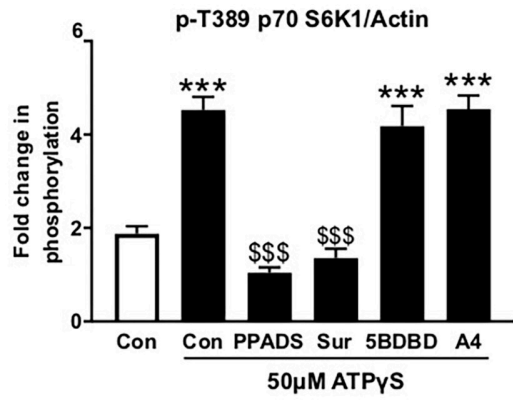

D

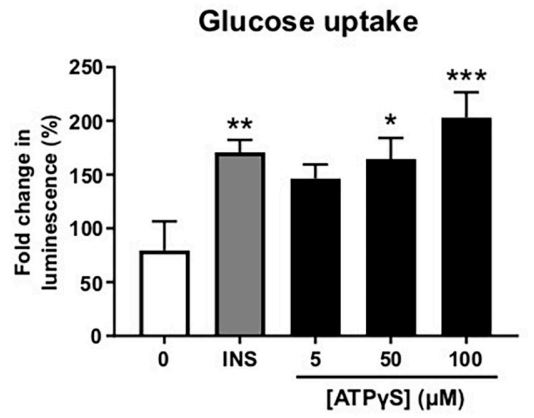

B

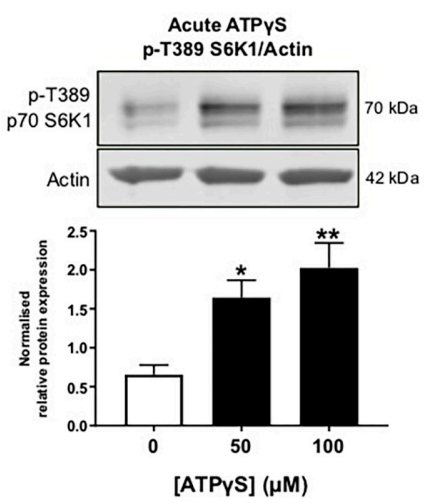

Ciii

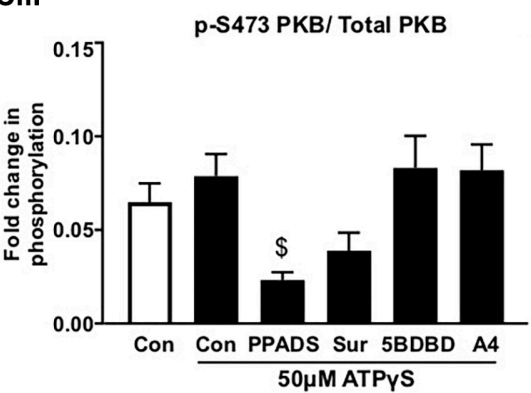

E

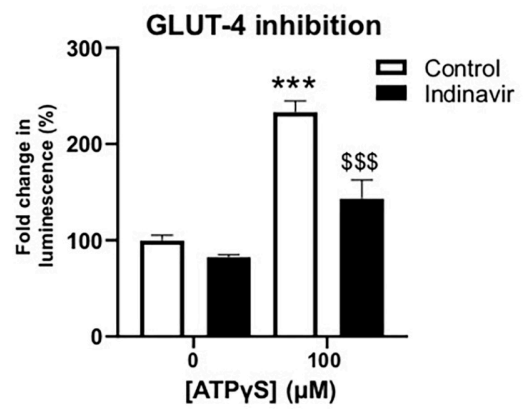

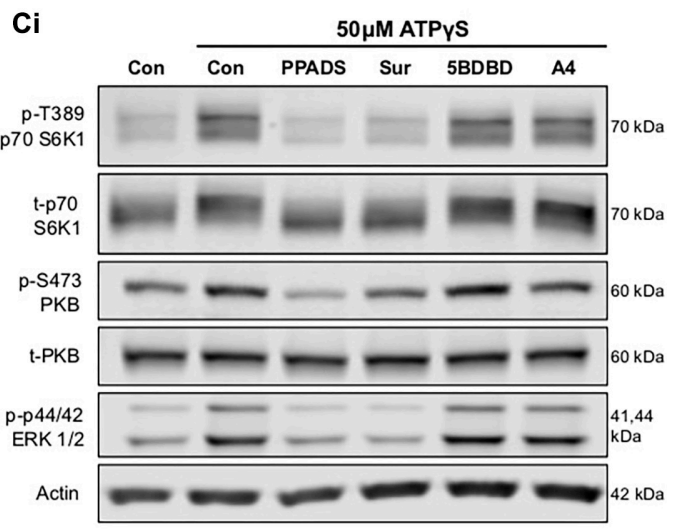

Civ

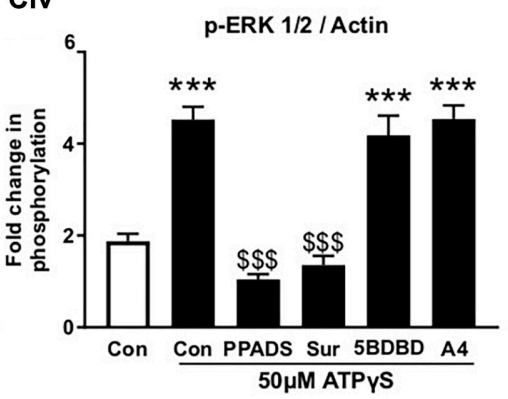

$\mathbf{F}$

Palmitate- glucose uptake

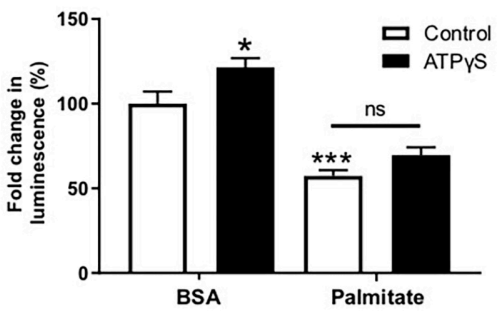

FIGURE 4 | ATP $\gamma$ S has insulin-mimetic roles in C2C12 myotubes activating PI3K/PKB and mTOR pathway signaling proteins in a P2-receptor-dependent manner and enhancing GLUT4-mediated glucose uptake. (A,B) Representative immunoblots for PKB (pS473) normalized to PKB (A; $n=5)$ and p70-S6K1 (pT389) normalized to p70-S6K1 (B; $n=6$ ) with densitometric analysis below for cells treated with ATP $\gamma \mathrm{S}(50-100 \mu \mathrm{M} ; 15$ min). (Ci) Representative immunoblots for PKB (pS473), PKB, p70-S6K1 (pT389), p70-S6K1, ERK 1/2 (pT202/TY204) and actin for cells treated with ATP $\gamma$ S (50 $\mu$ M; 15 min) with and without broad spectrum P2 receptor antagonists PPADs $(100 \mu \mathrm{M})$ and suramin $(100 \mu \mathrm{M})$, P2X4R antagonist 5-BDBD $(5 \mu \mathrm{M})$ and P2X7R antagonist A438079 (100 $\mu \mathrm{M})(45$ min prior to spiked ATP $\gamma S ; n=6)$. Densitometric analysis for p70-S6K1 (pT389) normalized to p70-S6K1 in (Cii); PKB (pS473) normalized to PKB in (Ciii) and ERK 1/2 (pT202/TY204) normalized to actin in (Civ). (D) Glucose uptake (2-DG; $100 \mu \mathrm{M} ; 15 \mathrm{~min}$ ) assessed by luminescence following treatment with ATP $\gamma \mathrm{S}(0-100 \mu \mathrm{M} ; 15 \mathrm{~min}$ pre-treatment) or insulin (200 nM; 15 min pre-treatment) $(n=9)$. (E) Glucose uptake (2-DG; $100 \mu \mathrm{M} ; 15 \mathrm{~min}$ ) following treatment with ATP $\gamma \mathrm{S}(100 \mu \mathrm{M} ; 15 \mathrm{~min})$ in the presence or absence of GLUT4 inhibitor indinavir $(50 \mu \mathrm{M})(n=5)$. (F) Glucose uptake (2-DG; $100 \mu \mathrm{M} ; 15 \mathrm{~min})$ following treatment with palmitate (500 $\mu \mathrm{M}$; 16 h) and ATP $\gamma \mathrm{S}(100 \mu \mathrm{M} ; 15 \mathrm{~min})(n=17) .{ }^{*} P<0.05 ;{ }^{* *} P<0.01 ;{ }^{* \star *} P<0.001$ against untreated control, $\$ \$ \$ P<0.001$ against ATP $\gamma S$ control. 
indinavir attenuated ATP $\gamma$ S-mediated glucose uptake by $40 \%$ (Figure 4E). To assess whether ATP $\gamma \mathrm{S}$-mediated glucose uptake was sustained in insulin resistant myotubes, we assessed glucose uptake following palmitate treatment and demonstrated that palmitate significantly attenuated basal and ATP $\gamma \mathrm{S}$-stimulated glucose uptake (Figure 4F).

\section{ATP $\mathbf{S}$ Increases Glycolytic Metabolism by a P2R-Dependent Mechanism}

To examine whether the enhancement in glucose uptake led to altered intracellular glucose metabolism, we performed a glycolysis stress test in the presence and absence of ATP $\gamma S$ and $\mathrm{P} 2 \mathrm{R}$ antagonists. Acute injection of ATP $\gamma \mathrm{S}$ induced a modest but statistically significant increase in the extracellular acidification rate (ECAR), in the absence of glucose (Figures 5Ai,ii). This response was abolished by PPADs but not by suramin, indicating this acute response is unlikely to be mediated by purely the addition of ATP $\gamma \mathrm{S}$. In the presence of suramin, ATP $\gamma \mathrm{S}$ generated a large increase in ECAR (Figures 5Ai,ii). This was not accompanied by increased oxygen consumption rate (OCR; data not shown) suggesting this is not mediated by $\mathrm{CO}_{2}$ production from the mitochondria. On addition of glucose, ATP $\gamma \mathrm{S}$ treatment augmented the ECAR response, suggesting enhanced glycolysis. Again, this was blocked by PPADs, but not by suramin
(Figures 5Ai,iii). We next examined the effect of chronic $(16 \mathrm{~h}) \mathrm{ATP} \gamma \mathrm{S}$ treatment on glycolytic function. Correspondingly, $\mathrm{ATP} \gamma \mathrm{S}$ significantly enhanced glycolysis. In this paradigm, pre-incubation with suramin prevented the enhanced ECAR response to glucose injection by $\mathrm{ATP} \gamma \mathrm{S}$, producing ECAR levels similar to control (Figures 5Bi,ii). Non-glycolytic acidification (before injection of glucose) was not altered by ATP $\gamma \mathrm{S}$ pretreatment (Figure 5Biii).

\section{DISCUSSION}

Skeletal muscle insulin resistance contributes substantially to the pathophysiology of T2D. Defining the pathways of insulin resistance and uncovering potential mechanisms to improve insulin sensitivity are key therapeutic areas requiring further investigation. It has previously been reported that palmitate induces release of ATP in skeletal muscle, which can recruit immune cells (Pillon et al., 2014). In liver, saturated fatty acids also increase hemi-channel expression to increase ATP release which can stimulate apoptosis (Xiao et al., 2012). Moreover, the action of ATP at P2Rs is a potent modulator of proinflammatory cytokine production and release in a number of non-immune cells including keratinocytes (Kawano et al., 2015), endothelial cells (Seiffert et al., 2006) and astrocytes
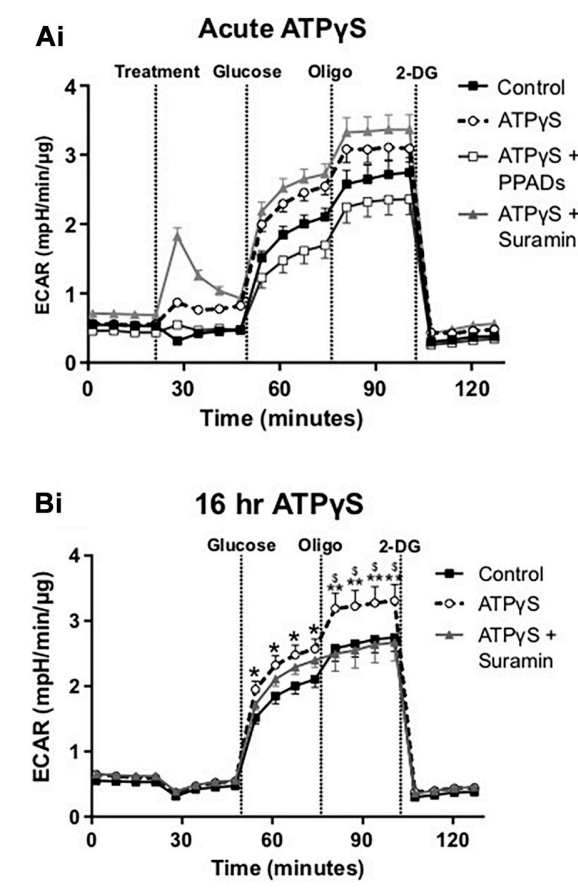

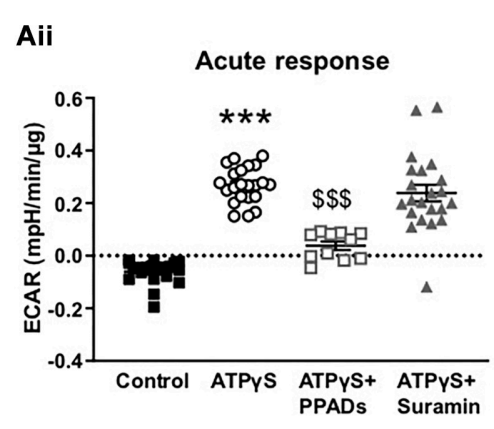

Bii

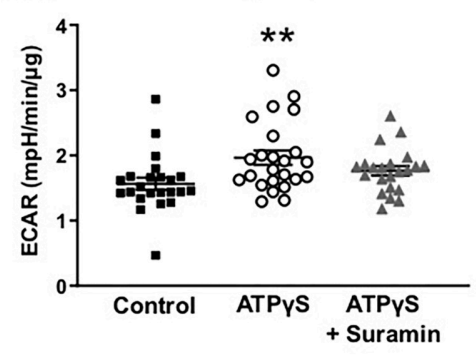

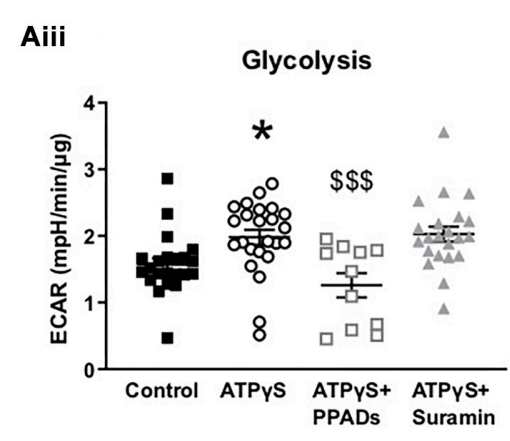

Bii Non-glycolytic acidification

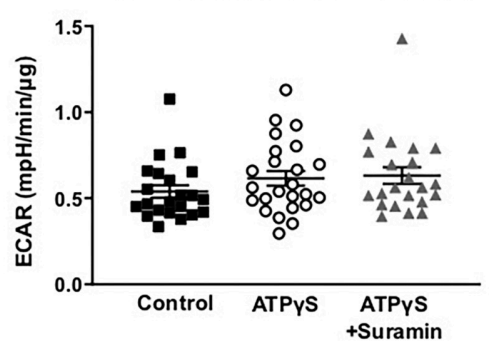

FIGURE 5 | Treatment with ATP $\gamma$ S enhances extracellular acidification rate in C2C12 myotubes in a P2-receptor-dependent and insulin-independent manner. (Ai) Representative extracellular flux assay demonstrating changes to glycolytic rate as estimated by extracellular acidification rate (ECAR) in response treatment with ATP $\gamma$ S (100 pM; treatment) with or without suramin (100 pM), PPADs (100 pM) or vehicle; followed by acute injection of glucose (5.5 mM), oligomycin (2 pM) and 2DG (50 mM) at the indicated points $(n=22-24)$. (Aii) Acute response, ECAR prior to glucose (Aiii) Glycolysis measured as the change in ECAR following glucose injection. (Bi) Representative extracellular flux assay for cells treated with ATP $\gamma \mathrm{S}$ (100 pM; $16 \mathrm{~h}$ ) with or without suramin (100 pM) or vehicle and acute injection of glucose $(5.5 \mathrm{mM})$, oligomycin (2 pM) and 2-DG (50 mM) at the indicated points $(n=22-24)$. (Bii) Glycolysis measured as the change in ECAR following glucose injection. (Biii) Non-glycolytic acidification demonstrating mean ECAR prior to glucose injection. Data represented as mean $\pm \mathrm{SEM}$. ${ }^{\star} P<0.05$; ${ }^{\star \star} P<0.01$; ${ }^{\star \star \star} P<0.001$ against control, $\$ P<0.05, \$ \$ P<0.001$ against ATP $\gamma$. 
(Liu et al., 2000). Therefore, given the role of ATP in mediating pro-inflammatory signaling, we postulated that ATP release from skeletal muscle, in an autocrine/paracrine manner and independently of immune cell recruitment, may contribute to production of pro-inflammatory cytokines and reduced insulin sensitivity in palmitate challenged myotubes. Here we utilized the $\mathrm{C} 2 \mathrm{C} 12$ myoblast cell line, differentiated into myotubes, to observed ATP release and exogenous ATP signaling in a cell autonomous manner. We demonstrate that palmitate induces ATP release from skeletal muscle myotubes independently of cell death, assessed by measurement of extracellular lactate dehydrogenase, agreeing with previous reports demonstrating palmitate-induced ATP release in a regulated manner (Pillon et al., 2014). In our study, palmitate-induced ATP release was accompanied by reduced insulin/AA sensitivity, diminished mitochondrial function and increased release of cytokines IL-6 and MIF. Contrary to our hypothesis, degradation of eATP using apyrase did not modify palmitate-induced insulin resistance nor cytokine release. In contrast, enhanced eATP signaling (in the absence of palmitate) produced insulin mimetic actions; increasing PKB, S6K1 and ERK1/2 phosphorylation. Recently, Ito and colleagues observed eATP-mediated increases in S6K1 and protein synthesis in $\mathrm{C} 2 \mathrm{C} 12$ myotubes, mediated by the P2Y2 receptor (Ito et al., 2018). Our findings are in line with these observations and suggest that eATP has anabolic actions in muscle.

We also observed increased GLUT4-mediated glucose uptake into $\mathrm{C} 2 \mathrm{C} 12$ myotubes following ATP $\gamma \mathrm{S}$ treatment, in line with previous reports (Osorio-Fuentealba et al., 2013). Exercise significantly increases ATP demand/turnover in muscle (Gaitanos et al., 1993) and palmitate-induced mitochondrial dysfunction leads to reduced ATP production (Nisr and Affourtit, 2016) and, interestingly, ATP release occurs in both situations (Osorio-Fuentealba et al., 2013; Pillon et al., 2014). Contraction and exercise-induced ATP release contributes to glucose uptake and cytokine release in skeletal muscle (Osorio-Fuentealba et al., 2013; Bustamante et al., 2014). If sensitivity to ATP-induced glucose uptake is sustained in insulin resistant states, this may contribute to exercised-induced anabolism and provide a novel therapeutic strategy to maintain glucose homeostasis in T2D. We tested the acute response to ATP $\gamma \mathrm{S}$ following palmitate treatment, mimicking contraction-induced ATP release in insulin resistant conditions, and demonstrated attenuated ATPsimulated uptake in palmitate-challenged cells, suggesting a level of purinergic resistance. Resistance to ATP-mediated glucose uptake has been demonstrated at lower ATP concentrations in muscle fibers from high-fat fed mice, but not at higher ATP concentrations, where response is sustained \{Osorio-Fuentealba et al., 2013 \#5679\}. Additional experimentation is required to investigate purinergic sensitivity in metabolically impaired skeletal muscle. However, others have demonstrated diminished $\mathrm{P} 2 \mathrm{R}$ responses to ATP in insulin resistant conditions, such as dampened P2Y2R-mediated vasodilation in T2D (Thaning et al., 2010), indicating that purinergic resistance could also occur at the level of glucose uptake and metabolism.

Our novel observations that ATP $\gamma S$ enhances skeletal muscle cell glycolytic function suggests an important receptor-mediated process to increase ATP generation as a positive feedback mechanism. Similar increases in cellular metabolism have been reported previously in endothelial cells, where exogenous ATP increased ECAR and upregulated key glycolytic enzymes including hexokinase, glucose transporter 1 expression and phosphofructokinase B3 (Lapel et al., 2017). This effect of eATP on metabolism is likely tissue specific as eATP has been reported to decrease cellular oxygen consumption in kidney cells, in a manner sensitive to suramin (Silva and Garvin, 2009). It is also worth noting that PPADs and suramin differentially blocked the effect of ATP $\gamma S$ on metabolism in this study, indicating that both P2X and P2YRs may contribute to glucose uptake and/or metabolism. Interestingly, blockade of G-protein signaling only partially attenuated ATP-induced glucose uptake (Osorio-Fuentealba et al., 2013), suggesting a component of glucose transport could be P2XR mediated. However, it is important to note that purinergic receptor and ATPase expression can change during differentiation (Martinello et al., 2011) and varies across species (Abdelmoez et al., 2020), therefore determining the receptor(s) in human skeletal muscle going forward will be important.

In our study, ATP $\gamma$ S also increased IL- 6 and decreased MIF release from myotubes. In general, transient and short-term muscle-derived IL-6, such as seen during exercise, promotes hypertrophy, myogenesis and regeneration (Fischer, 2006). IL-6 can also enhance skeletal muscle glucose uptake and fat oxidation via AMP-activated protein kinase dependent and independent pathways (Carey et al., 2006; Wolsk et al., 2010; Ikeda et al., 2016). Conversely, long-term elevation of IL-6, which is evident in inflammatory conditions, is associated with muscle wasting and IR (Kern et al., 2001; Pradhan et al., 2001; Rui et al., 2002). Therefore it is plausible that persistent fatty acid-induced ATP release drives chronic IL- 6 signaling to contribute to IR in an autocrine/paracrine fashion, in addition to the recruitment of immune cells (Pillon et al., 2014). Therefore the time course and persistence of the ATP release likely contributes to the differential response to acute (exercise-induced) versus chronic (palmitate-induced) ATP release. For example, a sustained elevation in eATP may be required to recruit and polarize immune cells toward a pro-inflammatory phenotype (Desai and Leitinger, 2014; Pillon et al., 2014). Furthermore, the physiological (increased ATP demand during contraction) and pathological context (impaired ATP production during excess lipid) may alter the outcome of eATP signaling, which requires further investigation.

Interestingly, ATP $\gamma \mathrm{S}$, in the absence of palmitate, decreased MIF release. MIF is a pro-inflammatory cytokine that is packaged into readily releasable pools (Bacher et al., 1997). The circulating levels of MIF are elevated in T2D (Yabunaka et al., 2000), Type 1 Diabetes (Bojunga et al., 2003; Ismail et al., 2016) and a number of other autoimmune diseases (Ayoub et al., 2008; Vincent et al., 2019). In addition, deletion of MIF in pancreatic beta cells protects them against palmitate-induced apoptosis (Saksida et al., 2012). In adipose tissue, MIF can inhibit insulin-stimulated glucose uptake (Atsumi et al., 2007) and in skeletal muscle, MIF can reduce insulin and AICAR-mediated glucose transport (Miyatake et al., 2014). Therefore, the significant decrease in MIF 
release following ATP $\gamma \mathrm{S}$ treatment suggests a possible beneficial effect of ATP $\gamma$ S.

Although not yet explored, it is also plausible that the benefits of neuromuscular electrical stimulation (NMES) in preventing disuse-induced atrophy during immobilization (Dirks et al., 2014) are partly attributed to the autocrine anabolic roles of eATP. This contraction-induced ATP release to the muscle interstitium (Mortensen et al., 2009) is mirrored by a transient increase in plasma ATP which increases and returns to basal levels within $30 \mathrm{~min}$ of recovery (Zarêbska et al., 2018). Utilizing ATP as a signal in this manner has a number of advantages specifically in muscle. For example, muscle contraction causes plasma membrane damage (McNeil and Khakee, 1992), leading to release of intracellular contents (including ATP); differentiated muscle cells express high levels of ATPases (Martinello et al., 2011) that rapidly degrade eATP allowing swift termination of the signal; and eATP can contribute to enhanced blood flow and oxygenation into muscle (Rosenmeier et al., 2008; Mortensen et al., 2009), which is essential during exercise. Whether this can be exploited as a therapy remains to be determined. Distinguishing physiological versus pharmacological actions of ATP will be important going forward, particularly during different states such as exercise or nutrient excess. However, in humans, oral ATP supplementation has been reported to increase muscle blood flow (Jäger et al., 2014) and size following resistance training (Wilson et al., 2013). It can also promote hypotension after exercise in hypertensive women (de Freitas et al., 2018). The reasons for the benefits of oral ATP remain unknown given that the bioavailability of oral ATP is very low (Arts et al., 2012) and that direct infusion of ATP into the femoral vein failed to increase interstitial ATP concentrations (Mortensen et al., 2009), which suggests that oral ATP itself is unlikely to be useful for improving glucose control. Whether a small molecular P2R agonist, delivered systemically, could replicate the benefits of eATP reported here will be important to determine. A better understanding of the purinergic regulation of glucose uptake, metabolism and cytokine release in conditions with compromised insulin and anabolic sensitivity is required to assess therapeutic potential of this system.

In summary, we show that extracellular ATP release does not contribute to reduced insulin sensitivity induced by palmitate in skeletal muscle myotubes but does increase glucose uptake and metabolism by a P2R-dependent mechanism. Importantly, the cytokine profile generated by ATP/ATP $\gamma \mathrm{S}$ is similar to the signature generated by moderate and high intensity exercise, which has been shown to increases muscle and plasma ATP levels;

\section{REFERENCES}

Abdelmoez, A. M., Puig, L. S., Smith, J.A. B., Gabriel, B. M., Savikj, M., Dollet, L., et al. (2020). Comparative profiling of skeletal muscle models reveals heterogeneity of transcriptome and metabolism. Am. J. Physiol. Cell Physiol. 318, C615-C626.

Abdul-Ghani, M. A., Muller, F. L., Liu, Y., Chavez, A. O., Balas, B., Zuo, P., et al. (2008). Deleterious action of FA metabolites on ATP synthesis: possible link between lipotoxicity, mitochondrial dysfunction, and insulin resistance. Am. J. Physiol. Endocrinol. Metab. 295, E678-E685. increase skeletal muscle glucose uptake (Carey et al., 2006; Ikeda et al., 2016); increase circulating levels of IL-6 (Sprenger et al., 1992) and to decrease circulating MIF levels (Wahl et al., 2014). The potential for the exercise mimetic actions of ATP and P2R modulation in skeletal muscle to treat conditions such as T2D requires further study.

\section{DATA AVAILABILITY STATEMENT}

The raw data supporting the conclusions of this article will be made available by the authors, without undue reservation.

\section{AUTHOR CONTRIBUTIONS}

AC designed and performed experiments, analyzed data and contributed to interpretation of data and writing of the manuscript. CB conceived the study, contributed to experimental design and wrote the manuscript. Both authors agree to be accountable for the content of the work.

\section{FUNDING}

This study was funded by a Diabetes United Kingdom RD Lawrence Fellowship to CB (13/0004647), a Northcott Devon Medical Foundation grant to $\mathrm{CB}$ and $\mathrm{AC}$ and a University of Exeter Medical School Ph.D. studentship for AC.

\section{ACKNOWLEDGMENTS}

We wish to thank Benjamin Wall (University of Exeter), Dr. Lee Hamilton (University of Stirling) and Dr. Kate Ellacott (University of Exeter) for insightful discussions and suggestions. We also thank Dr. Amy Cameron (University of Dundee) and Julia Vlachaki Walker (University of Exeter) for important technical contributions. All data in this paper appears in the Ph.D. thesis of Dr. Ana Cruz.

\section{SUPPLEMENTARY MATERIAL}

The Supplementary Material for this article can be found online at: https://www.frontiersin.org/articles/10.3389/fphys. 2020.567378/full\#supplementary-material

Aguer, C., McCoin, C. S., Knotts, T. A., Thrush, A. B., Ono-Moore, K., McPherson, R., et al. (2015). Acylcarnitines: potential implications for skeletal muscle insulin resistance. FASEB J. 29, 336-345. doi: 10.1096/fj.14-255901

Anderson, S. R., Gilge, D. A., Steiber, A. L., and Previs, S. F. (2008). Diet-induced obesity alters protein synthesis: tissue-specific effects in fasted versus fed mice. Metabolism 57, 347-354. doi: 10.1016/j.metabol.2007.10.009

Arts, I. C. W., Coolen, E. J. C. M., Bours, M. J. L., Huyghebaert, N., Stuart, M., Bast, A., et al. (2012). Adenosine 5'-triphosphate (ATP) supplements are not orally bioavailable: a randomized, placebo-controlled cross-over trial in healthy humans. J. Int. Soc. Sports Nutr. 9:16. 
Atsumi, T., Cho, Y. R., Leng, L., McDonald, C., Yu, T., Danton, C., et al. (2007). The proinflammatory cytokine macrophage migration inhibitory factor regulates glucose metabolism during systemic inflammation. J. Immunol. 179, 5399-5406. doi: 10.4049/jimmunol.179.8.5399

Ayoub, S., Hickey, M. J., and Morand, E. F. (2008). Mechanisms of Disease: macrophage migration inhibitory factor in SLE, RA and atherosclerosis. Nat. Clin. Pract. Rheumatol. 4, 98-105. doi: 10.1038/ncprheum0701

Bacher, M., Meinhardt, A., Lan, H. Y., Mu, W., Metz, C. N., Chesney, J. A., et al. (1997). Migration inhibitory factor expression in experimentally induced endotoxemia. Am. J. Pathol. 150, 235-246.

Barnes, T. M., Otero, Y. F., Elliott, A. D., Locke, A. D., Malabanan, C. M., Coldren, A. G., et al. (2014). Interleukin-6 amplifies glucagon secretion: coordinated control via the brain and pancreas. Am. J. Physiol. Endocrinol. Metab. 307, E896-E905.

Beals, J. W., Sukiennik, R. A., Nallabelli, J., Emmons, R. S., van Vliet, S., Young, J. R., et al. (2016). Anabolic sensitivity of postprandial muscle protein synthesis to the ingestion of a protein-dense food is reduced in overweight and obese young adults. Am. J. Clin. Nutr. 104, 1014-1022. doi: 10.3945/ajcn.116.130385

Bergman, B. C., and Goodpaster, B. H. (2020). Exercise and muscle lipid content, composition, and localization: influence on muscle insulin sensitivity. Diabetes Metab. Res. Rev. 69, 848-858. doi: 10.2337/dbi18-0042

Bojunga, J., Kusterer, K., Bacher, M., Kurek, R., Usadel, K. H., and Renneberg, H. (2003). Macrophage migration inhibitory factor and development of type-1 diabetes in non-obese diabetic mice. Cytokine 21, 179-186. doi: 10.1016/s10434666(03)00076-0

Brandt, C., Jakobsen, A. H., Adser, H., Olesen, J., Iversen, N., Kristensen, J. M., et al. (2012). IL-6 regulates exercise and training-induced adaptations in subcutaneous adipose tissue in mice. Acta Physiol. 205, 224-235. doi: 10.1111/ j.1748-1716.2011.02373.x

Bustamante, M., Fernández-Verdejo, R., Jaimovich, E., and Buvinic, S. (2014). Electrical stimulation induces IL-6 in skeletal muscle through extracellular ATP by activating $\mathrm{Ca}(2+)$ signals and an IL-6 autocrine loop. Am. J. Physiol. Endocrinol. Metab. 306, E869-E882.

Buvinic, S., Almarza, G., Bustamante, M., Casas, M., López, J., Riquelme, M., et al. (2009). ATP released by electrical stimuli elicits calcium transients and gene expression in skeletal muscle. J. Biol. Chem. 284, 34490-34505. doi: 10.1074/ jbc.m109.057315

Carey, A. L., Steinberg, G. R., Macaulay, S. L., Thomas, W. G., Holmes, A. G., Ramm, G., et al. (2006). Interleukin-6 increases insulin-stimulated glucose disposal in humans and glucose uptake and fatty acid oxidation in vitro via AMP-activated protein kinase. Diabetes Metab. Res. Rev. 55, 2688-2697. doi: 10.2337/db05-1404

Chatterjee, C., and Sparks, D. L. (2012). Extracellular nucleotides inhibit insulin receptor signaling, stimulate autophagy and control lipoprotein secretion. PLoS One 7:e36916. doi: 10.1371/journal.pone.0036916

Cseri, J., Szappanos, H., Szigeti, G., Csernátony, Z., Kovács, L., and Csernoch, L. (2002). A purinergic signal transduction pathway in mammalian skeletal muscle cells in culture. Pflügers Arch. 443, 731-738. doi: 10.1007/s00424-001-0757-x

Dandona, P., Aljada, A., Ghanim, H., Mohanty, P., Tripathy, C., Hofmeyer, D., et al. (2004). Increased plasma concentration of macrophage migration inhibitory factor (MIF) and MIF mRNA in mononuclear cells in the obese and the suppressive action of metformin. J. Clin. Endocrinol. Metab. 89, 5043-5047. doi: $10.1210 /$ jc.2004-0436

de Freitas, M. C., Ricci-Vitor, A. L., Freire, R. V., Caperuto, E. C., Vanderlei, L.C. M., Lira, F. S., et al. (2018). Oral adenosine 5'-triphosphate supplementation improved hemodynamic and autonomic parameters after exercise in hypertensive women. J. Exerc. Rehabil. 14, 671-679. doi: 10.12965/ jer. 1836256.128

Desai, B. N., and Leitinger, N. (2014). Purinergic and calcium signaling in macrophage function and plasticity. Front. Immunol. 5:580. doi: 10.3389/ fimmu.2014.00580

Dirks, M. L., Wall, B. T., Snijders, T., Ottenbros, C. L., Verdijk, L. B., and van Loon, L. J. (2014). Neuromuscular electrical stimulation prevents muscle disuse atrophy during leg immobilization in humans. Acta Physiol. 210, 628-641. doi: 10.1111/apha.12200

Eckardt, K., Görgens, S. W., Raschke, S., and Eckel, J. (2014). Myokines in insulin resistance and type 2 diabetes. Diabetologia 57, 1087-1099. doi: 10.1007/ s00125-014-3224-x
Ellis, B. A., Poynten, A., Lowy, A. J., Furler, S. M., Chisholm, D. J., Kraegen, E. W., et al. (2000). Long-chain acyl-CoA esters as indicators of lipid metabolism and insulin sensitivity in rat and human muscle. Am. J. Physiol. Endocrinol. Metab. 279, E554-E560.

Enjyoji, K., Kotani, K., Thukral, C., Blumel, B., Sun, X., Wu, Y., et al. (2008). Deletion of cd39/entpd1 results in hepatic insulin resistance. Diabetes Metab. Res. Rev. 57, 2311-2320. doi: 10.2337/db07-1265

Fischer, C. P. (2006). Interleukin-6 in acute exercise and training: what is the biological relevance? Exerc. Immunol. Rev. 12, 6-33.

Gaitanos, G. C., Williams, C., Boobis, L. H., and Brooks, S. (1993). Human muscle metabolism during intermittent maximal exercise. J. Appl. Physiol. 75, 712-719. doi: 10.1152/jappl.1993.75.2.712

Guillet, C., Delcourt, I., Rance, M., Giraudet, C., Walrand, S., Bedu, M., et al. (2009). Changes in basal and insulin and amino acid response of whole body and skeletal muscle proteins in obese men. J. Clin. Endocrinol. Metab. 94, 3044-3050. doi: 10.1210/jc.2008-2216

Ikeda, S. I., Tamura, Y., Kakehi, S., Sanada, H., Kawamori, R., and Watada, H. (2016). Exercise-induced increase in IL-6 level enhances GLUT4 expression and insulin sensitivity in mouse skeletal muscle. Biochem. Biophys. Res. Commun. 473, 947-952. doi: 10.1016/j.bbrc.2016.03.159

Ismail, N. A., Abd El Baky, A. N., Ragab, S., Hamed, M., Hashish, M. A., and Shehata, A. (2016). Monocyte chemoattractant protein 1 and macrophage migration inhibitory factor in children with type 1 diabetes. J. Pediatr. Endocrinol. Metab. 29, 641-645.

Itani, S. I., Ruderman, N. B., Schmieder, F., and Boden, G. (2002). Lipid-induced insulin resistance in human muscle is associated with changes in diacylglycerol, protein kinase C, and IkappaB-alpha. Diabetes Metab. Res. Rev. 51, 2005-2011. doi: 10.2337/diabetes.51.7.2005

Ito, N., Ruegg, U. T., and Takeda, S. (2018). ATP-induced increase in intracellular calcium levels and subsequent activation of mTOR as regulators of skeletal muscle hypertrophy. Int. J. Mol. Sci. 19:2804. doi: 10.3390/ijms19092804

Jäger, R., Roberts, M. D., Lowery, R. P., Joy, J. M., Cruthirds, C. L., Lockwood, C. M., et al. (2014). Oral adenosine-5'-triphosphate (ATP) administration increases blood flow following exercise in animals and humans. J. Int. Soc. Sports Nutr. 11:28. doi: 10.1186/1550-2783-11-28

Jove, M., Planavila, A., Laguna, J. C., and Vazquez-Carrera, M. (2005). Palmitateinduced interleukin 6 production is mediated by protein kinase $\mathrm{C}$ and nuclearfactor kappaB activation and leads to glucose transporter 4 down-regulation in skeletal muscle cells. Endocrinology 146, 3087-3095. doi: 10.1210/en.2004- 1560

Katz, L. D., Glickman, M. G., Rapoport, S., Ferrannini, E., and DeFronzo, R. A. (1983). Splanchnic and peripheral disposal of oral glucose in man. Diabetes Metab. Res. Rev. 32, 675-679. doi: 10.2337/diabetes.32.7.675

Kawano, A., Kadomatsu, R., Ono, M., Kojima, S., Tsukimoto, M., and Sakamoto, H. (2015). Autocrine regulation of UVA-induced IL-6 production via release of ATP and activation of P2Y receptors. PLoS One 10:e0127919. doi: 10.1371/ journal.pone.0127919

Kern, P. A., Ranganathan, S., Li, C., Wood, L., and Ranganathan, G. (2001). Adipose tissue tumor necrosis factor and interleukin-6 expression in human obesity and insulin resistance. Am. J. Physiol. Endocrinol. Metab. 280, E745E751.

Khan, I. M., Perrard, X. Y., Brunner, G., Lui, H., Sparks, L. M., Smith, S. R., et al. (2015). Intermuscular and perimuscular fat expansion in obesity correlates with skeletal muscle $\mathrm{T}$ cell and macrophage infiltration and insulin resistance. Int. J. Obes. 39, 1607-1618. doi: 10.1038/ijo.2015.104

Lapel, M., Weston, P., Strassheim, D., Karoor, V., Burns, N., Lyubchenko, T., et al. (2017). Glycolysis and oxidative phosphorylation are essential for purinergic receptor-mediated angiogenic responses in vasa vasorum endothelial cells. Am. J. Physiol. Cell Physiol. 312, C56-C70. doi: 10.1152/ajpcell.00250.2016

Liu, J. S., John, G. R., Sikora, A., Lee, S. C., and Brosnan, C. F. (2000). Modulation of interleukin-1beta and tumor necrosis factor alpha signaling by $\mathrm{P} 2$ purinergic receptors in human fetal astrocytes. J. Neurosci. 20, 5292-5299. doi: 10.1523/ jneurosci.20-14-05292.2000

Martinello, T., Baldoin, M. C., Morbiato, L., Paganin, M., Tarricone, E., Schiavo, G., et al. (2011). Extracellular ATP signaling during differentiation of C2C12 skeletal muscle cells: role in proliferation. Mol. Cell. Biochem. 351, 183-196. doi: 10.1007/s11010-011-0726-4

Masgrau, A., Mishellany-Dutour, A., Murakami, H., Beaufrère, A. M., Walrand, S., Giraudet, C., et al. (2012). Time-course changes of muscle protein synthesis 
associated with obesity-induced lipotoxicity. J. Physiol. 590, 5199-5210. doi: 10.1113/jphysiol.2012.238576

McNeil, P. L., and Khakee, R. (1992). Disruptions of muscle fiber plasma membranes. Role in exercise-induced damage. Am. J. Pathol. 140, 1097-1109.

Miyatake, S., Manabe, Y., Inagaki, A., Furuichi, Y., Takagi, M., Taoka, M., et al. (2014). Macrophage migration inhibitory factor diminishes muscle glucose transport induced by insulin and AICAR in a muscle type-dependent manner. Biochem. Biophys. Res. Commun. 444, 496-501. doi: 10.1016/j.bbrc.2014.01.089

Mortensen, S. P., Gonzalez-Alonso, J., Nielsen, J. J., Saltin, B., and Hellsten, Y. (2009). Muscle interstitial ATP and norepinephrine concentrations in the human leg during exercise and ATP infusion. J. Appl. Physiol. 107, 1757-1762. doi: 10.1152/japplphysiol.00638.2009

Murton, A. J., Marimuthu, K., Mallinson, J. E., Selby, A. L., Smith, K., Rennie, M. J., et al. (2015). Obesity appears to be associated with altered muscle protein synthetic and breakdown responses to increased nutrient delivery in older men, but not reduced muscle mass or contractile function. Diabetes Metab. Res. Rev. 64, 3160-3171. doi: 10.2337/db15-0021

Nisr, R. B., and Affourtit, C. (2016). Palmitate-induced changes in energy demand cause reallocation of ATP supply in rat and human skeletal muscle cells. Biochim. Biophys. Acta Bioenerget. 1857, 1403-1411.

Osorio-Fuentealba, C., Contreras-Ferrat, A. E., Altamirano, F., Espinosa, A., Li, Q., Niu, W., et al. (2013). Electrical stimuli release ATP to increase GLUT4 translocation and glucose uptake via PI3K $\gamma$-Akt-AS160 in skeletal muscle cells. Diabetes Metab. Res. Rev. 62, 1519-1526. doi: 10.2337/db12-1066

Pedersen, B. K., and Febbraio, M. A. (2008). Muscle as an endocrine organ: focus on muscle-derived interleukin-6. Physiol. Rev. 88, 1379-1406. doi: 10.1152/ physrev.90100.2007

Pendergrass, M., Bertoldo, A., Bonadonna, R., Nucci, G., Mandarino, L., Cobelli, C., et al. (2007). Muscle glucose transport and phosphorylation in type 2 diabetic, obese nondiabetic, and genetically predisposed individuals. Am. J. Physiol. Endocrinol. Metab. 292, E92-E100. doi: 10.1152/ajpendo.00617.2005

Petersen, M. C., and Shulman, G. I. (2018). Mechanisms of insulin action and insulin resistance. Physiol. Rev. 98, 2133-2223. doi: 10.1152/physrev.00063. 2017

Pillon, N. J., Li, Y. E., Fink, L. N., Brozinick, J. T., Nikolayev, A., Kuo, M. S., et al. (2014). Nucleotides released from palmitate-challenged muscle cells through pannexin-3 attract monocytes. Diabetes Metab. Res. Rev. 63, 3815-3826. doi: $10.2337 / \mathrm{db} 14-0150$

Pradhan, A. D., Manson, J. E., Rifai, N., Buring, J. E., and Ridker, P. M. (2001). Creactive protein, interleukin 6 , and risk of developing type 2 diabetes mellitus. JAMA 286, 327-334. doi: 10.1001/jama.286.3.327

Rosenmeier, J. B., Yegutkin, G. G., and Gonzalez-Alonso, J. (2008). Activation of ATP/UTP-selective receptors increases blood flow and blunts sympathetic vasoconstriction in human skeletal muscle. J. Physiol. 586, 4993-5002. doi: 10.1113/jphysiol.2008.155432

Rui, L., Yuan, M., Frantz, D., Shoelson, S., and White, M. F. (2002). SOCS-1 and SOCS-3 block insulin signaling by ubiquitin-mediated degradation of IRS 1 and IRS2. J. Biol. Chem. 277, 42394-42398. doi: 10.1074/jbc.C200444200

Saksida, T., Stosic-Grujicic, S., Timotijevic, G., Sandler, S., and Stojanovic, I. (2012). Macrophage migration inhibitory factor deficiency protects pancreatic islets from palmitic acid-induced apoptosis. Immunol. Cell Biol. 90, 688-698. doi: 10.1038/icb.2011.89

Seiffert, K., Ding, W., Wagner, J. A., and Granstein, R. D. (2006). ATPgammaS enhances the production of inflammatory mediators by a human dermal endothelial cell line via purinergic receptor signaling. J. Invest. Dermatol. 126, 1017-1027.

Sergi, D., Naumovski, N., Heilbronn, L. K., Abeywardena, M., O’Callaghan, N., Lionetti, L., et al. (2019). Mitochondrial (Dys)function and insulin resistance: from pathophysiological molecular mechanisms to the impact of diet. Front. Physiol. 10:532. doi: 10.3389/fphys.2019.00532

Silva, G. B., and Garvin, J. L. (2009). Extracellular ATP inhibits transport in medullary thick ascending limbs: role of P2X receptors. Am. J. Physiol. Renal Physiol. 297, F1168-F1173. doi: 10.1152/ajprenal.00325.2009

Sprenger, H., Jacobs, C., Nain, M., Gressner, A. M., Prinz, H., Wesemann, W., et al. (1992). Enhanced release of cytokines, interleukin-2 receptors, and neopterin after long-distance running. Clin. Immunol. Immunopathol. 63, 188-195. doi: 10.1111/j.1469-7793.2000.00237.x
Steensberg, A., van Hall, G., Osada, T., Sacchetti, M., Saltin, B., and Klarlund Pedersen, B. (2000). Production of interleukin-6 in contracting human skeletal muscles can account for the exercise-induced increase in plasma interleukin-6. J. Physiol. 529(Pt 1), 237-242.

Stephens, F. B., Chee, C., Wall, B. T., Murton, A. J., Shannon, C. E., van Loon, L. J., et al. (2015). Lipid-induced insulin resistance is associated with an impaired skeletal muscle protein synthetic response to amino acid ingestion in healthy young men. Diabetes Metab. Res. Rev. 64, 1615-1620. doi: 10.2337/db14-0961

Summers, S. A. (2006). Ceramides in insulin resistance and lipotoxicity. Prog. Lipid Res. 45, 42-72. doi: 10.1016/j.plipres.2005.11.002

Thaning, P., Bune, L. T., Hellsten, Y., Pilegaard, H., Saltin, B., and Rosenmeier, J. B. (2010). Attenuated purinergic receptor function in patients with type 2 diabetes. Diabetes Metab. Res. Rev. 59, 182-189. doi: 10.2337/db09-1068

Tozzi, M., and Novak, I. (2017). Purinergic receptors in adipose tissue as potential targets in metabolic disorders. Front. Pharmacol. 8:878. doi: 10.3389/fphar. 2017.00878

Vincent, F. B., Lang, T., Kandane-Rathnayake, R., Downie-Doyle, S., Morand, E. F., and Rischmueller, M. (2019). Serum and urinary macrophage migration inhibitory factor (MIF) in primary Sjögren's syndrome. Joint Bone Spine 86, 393-395. doi: 10.1016/j.jbspin.2018.07.001

Vlachaki Walker, J. M., Robb, J. L., Cruz, A. M., Malhi, A., Weightman Potter, P. G., Ashford, M., et al. (2017). AMP-activated protein kinase (AMPK) activator A-769662 increases intracellular calcium and ATP release from astrocytes in an AMPK-independent manner. Diabetes Obes. Metab. 19, 997-1005. doi: 10.1111/dom.12912

Wahl, P., Jansen, F., Achtzehn, S., Schmitz, T., Bloch, W., Mester, J., et al. (2014). Effects of high intensity training and high volume training on endothelial microparticles and angiogenic growth factors. PLoS One 9:e96024. doi: 10.1371/ journal.pone.0096024

Wall, B. T., Cruz, A. M., Otten, B., Dunlop, M. V., Fulford, J., Porter, C., et al. (2020). The impact of disuse and high-fat overfeeding on forearm muscle amino acid metabolism in humans. J. Clin. Endocrinol. Metab. 105:dgaa184. doi: $10.1210 /$ clinem/dgaa184

Wilson, J. M., Joy, J. M., Lowery, R. P., Roberts, M. D., Lockwood, C. M., Manninen, A. H., et al. (2013). Effects of oral adenosine-5'-triphosphate supplementation on athletic performance, skeletal muscle hypertrophy and recovery in resistance-trained men. Nutr. Metab. 10:57. doi: 10.1186/17437075-10-57

Wolsk, E., Mygind, H., Grondahl, T. S., Pedersen, B. K., and van Hall, G. (2010), IL-6 selectively stimulates fat metabolism in human skeletal muscle. Am. J. Physiol. Endocrinol. Metab. 299, E832-E840. doi: 10.1152/ajpendo.00328. 2010

Wu, H., and Ballantyne, C. M. (2017). Skeletal muscle inflammation and insulin resistance in obesity. J. Clin. Invest. 127, 43-54. doi: 10.1172/JCI88880

Xiao, F., Waldrop, S. L., Khimji, A. K., and Kilic, G. (2012). Pannexin1 contributes to pathophysiological ATP release in lipoapoptosis induced by saturated free fatty acids in liver cells. Am. J. Physiol. Cell Physiol. 303, C1034-C1044. doi: 10.1152/ajpcell.00175.2012

Yabunaka, N., Nishihira, J., Mizue, Y., Tsuji, M., Kumagai, M., Ohtsuka, Y., et al. (2000). Elevated serum content of macrophage migration inhibitory factor in patients with type 2 diabetes. Diabetes Care 23, 256-258. doi: 10.2337/diacare. 23.2.256

Zarêbska, E. A., Kusy, K., Słomiñska, E. M., Kruszyna, Ł, and Zieliñski, J. (2018). Plasma nucleotide dynamics during exercise and recovery in highly trained athletes and recreationally active individuals. BioMed Res. Int. 2018:4081802. doi: $10.1155 / 2018 / 4081802$

Conflict of Interest: The authors declare that the research was conducted in the absence of any commercial or financial relationships that could be construed as a potential conflict of interest.

Copyright () 2020 Cruz and Beall. This is an open-access article distributed under the terms of the Creative Commons Attribution License (CC BY). The use, distribution or reproduction in other forums is permitted, provided the original author(s) and the copyright owner(s) are credited and that the original publication in this journal is cited, in accordance with accepted academic practice. No use, distribution or reproduction is permitted which does not comply with these terms. 